\title{
Neurophysiological Markers of Alzheimer's Disease: Quantitative EEG Approach
}

Una Smailovic · Vesna Jelic

\begin{abstract}
Currently established and employed biomarkers of Alzheimer's disease (AD) predominantly mirror AD-associated molecular and structural brain changes. While they are necessary for identifying disease-specific neuropathology, they lack a clear and robust relationship with the clinical presentation of dementia; they can be altered in healthy individuals, while they often inadequately mirror the degree of cognitive and functional deficits in affected subjects. There is growing evidence that synaptic loss and dysfunction are early events during the trajectory of $\mathrm{AD}$ pathogenesis that best correlate with the clinical symptoms, suggesting measures of
\end{abstract}

Enhanced Digital Features To view enhanced digital features for this article go to https://doi.org/10.6084/ m9.figshare.9792227.

U. Smailovic ( $\square)$

Division of Clinical Geriatrics, Department of

Neurobiology, Care Sciences and Society, Karolinska Institutet, Huddinge, Sweden

e-mail: Una.smailovic@ki.se

V. Jelic

Division of Clinical Geriatrics, Department of Neurobiology, Care Sciences and Society, Karolinska Institutet and Clinic for Cognitive Disorders, Theme Aging, Karolinska University Hospital, Huddinge, Sweden brain functional deficits as candidate early markers of AD. Resting-state electroencephalography (EEG) is a widely available and noninvasive diagnostic method that provides direct insight into brain synaptic activity in real time. Quantitative EEG (qEEG) analysis additionally provides information on physiologically meaningful frequency components, dynamic alterations and topography of EEG signal generators, i.e. neuronal signaling. Numerous studies have shown that qEEG measures can detect disruptions in activity, topographical distribution and synchronization of neuronal (synaptic) activity such as generalized EEG slowing, reduced global synchronization and anteriorization of neuronal generators of fast-frequency resting-state EEG activity in patients along the $\mathrm{AD}$ continuum. Moreover, qEEG measures appear to correlate well with surrogate markers of $\mathrm{AD}$ neuropathology and discriminate between different types of dementia, making them promising low-cost and noninvasive markers of AD. Future large-scale longitudinal clinical studies are needed to elucidate the diagnostic and prognostic potential of qEEG measures as early functional markers of $\mathrm{AD}$ on an individual subject level.

Keywords: Alzheimer's disease; Biomarkers; Quantitative electroencephalography; Functional markers 


\section{Key Summary Points}

Quantitative EEG (qEEG) is a noninvasive method that mirrors synaptic (dys)function in real time.

Generalized EEG slowing, decreased EEG synchronization and frontal shift of neuronal generators of fast frequencies have been repeatedly reported across the clinical continuum of Alzheimer's disease (AD).

qEEG measures correlate with molecular and imaging $\mathrm{AD}$ biomarkers and discriminate between different types of dementia.

qEEG measures are potential early and noninvasive markers of synaptic dysfunction in $\mathrm{AD}$ patients.

Future large-scale longitudinal studies are needed to confirm diagnostic and prognostic potential of qEEG measures on an individual level.

\section{INTRODUCTION}

For more than a decade, massive efforts and investments in dementia drug discovery platforms have failed to yield a successful result [1]. Alzheimer's dementia is the most common form of dementia, whose pathophysiological mechanisms, early diagnostic markers and drug candidates have been particularly extensively investigated. Despite discouraging results from clinical drug trials, the field has come to an important realization: conventional markers of Alzheimer's disease (AD) used as diagnostic markers and/or secondary outcome measures do not sufficiently mirror clinically relevant effects, i.e. changes in cognitive functions in $\mathrm{AD}$ patients [2]. Moreover, patients with the same extent of AD neuropathological alterations in the brain, such as brain atrophy and/or amyloid accumulation, have been shown to exhibit different levels of cognitive impairment, and vice versa. This notion, known as brain and cognitive reserve, is explained by the individual differences in resilience to AD-related neuropathology [3]. Together, these findings have motivated the pursuit of novel biomarkers that would help bridge the gap between the clinical symptomatology, disease pathology and individual vulnerability to the biological substrates of the disease. The gradual clinical manifestation of $\mathrm{AD}$, from subjective (preclinical) through mild (early clinical) cognitive impairment (subjective cognitive decline [SCD] and mild cognitive impairment [MCI], respectively $[4,5])$, has also driven the search for biomarkers towards the early stages of this insidious disease.

This review paper discusses the potential for quantitative electroencephalography (qEEG) to serve as an early and noninvasive marker of synaptic dysfunction in patients along the $\mathrm{AD}$ continuum.

This article is based on previously conducted studies and does not involve any new studies of human or animal subjects performed by any of the authors.

\section{SYNAPTIC DYSFUNCTION IN ALZHEIMER'S DISEASE}

Conventional markers of $\mathrm{AD}$ reflect amyloid and tau pathology, as the core neuropathological elements of the disease [6]. The histological features of abnormal accumulation of these two proteins, amyloid plaques and neurofibrillary tangles, have been first observed and described at the same time as the clinical symptoms of the disease itself [7]. However, the field has recently shifted its focus towards methods and markers that might reveal $\mathrm{AD}$-associated disturbances in brain function rather than simply in structure. This was motivated by numerous studies that have shown that synaptic dysfunction and loss such as decreased synaptic density in neocortex and limbic regions, seem to be an early event in $\mathrm{AD}$, present already in the pre-dementia (MCI) stage of the disease [8-11]. Moreover, assembly of amyloid $\beta$ protein $(A \beta)$ into oligomers, presumably the most toxic amyloid species in the brain, during the $\mathrm{AD}$ pathophysiological 
process has been shown to disrupt synaptic function and structure, deplete synaptic number and consequently impair memory $[12,13]$. In addition to the direct deleterious effect on synapses, recent findings provide evidence that $\mathrm{A} \beta$ oligomers have the potential to indirectly impair synaptic and neuronal activity by inducing $\mathrm{AD}$-associated tau pathology, neuritic degeneration and neuroinflammation [12, 14-16]. Altogether, synaptic loss, being more extensive than neuronal loss when analyzed in the same brain regions, has been shown to be the best neuropathological correlate of cognitive impairment in patients along the $\mathrm{AD}$ continuum $[8,11,17,18]$.

\section{SYNAPTIC MARKERS: EEG TAKES SPOTLIGHT}

EEG reflects the real-time functioning of brain synapses. EEG oscillatory signals, recorded at the level of the scalp, mainly result from the summated excitatory and inhibitory postsynaptic potentials generated by the patches of pyramidal neurons in the brain gray matter. Pyramidal cells are spatially aligned and perpendicular to the cortical surface, which allows them to generate current flow that can be recorded by EEG as scalp potentials [19]. Eyesclosed resting-state EEG recordings are performed as standard procedure in the clinical setting. In addition to EEG, diagnostic methods such as functional magnetic resonance imaging (fMRI), fluorodeoxyglucose PET imaging (FDGPET) or magnetoencephalography (MEG) are available for assessment of brain synaptic function. Functional MRI and FDG-PET are valuable research and clinical imaging methods, but have limited time resolution and resemble metabolic signals, i.e. indirect neuronal signaling only [19]. MEG shares many similarities with EEG; it measures the magnetic field perpendicular to the direction of the electrical current generated by neurons, but is currently used mainly in research settings [20]. Transcranial magnetic stimulation (TMS) has recently emerged as a noninvasive neurophysiological tool with the potential to detect disturbances in long-term potentiation (LTP)-like cortical plasticity, and hence synaptic activity in $\mathrm{AD}$ patients [21]. However, TMS as a diagnostic tool has yet to be validated in the context of research and clinical dementia assessment. At the same time, increasing attention has been dedicated to the development of in vivo synaptic imaging methods, such as synaptic vesicle protein $2 \mathrm{~A}$ (SV2A) PET imaging, which would provide invaluable spatial information on synaptic density and degeneration [22]. Even though decreased levels of SV2A in the brain tissue have already been described in AD patients [23], the exact function of the protein, its role in the disease and the properties of several available radioligands have yet to be elucidated [22].

Routine resting-state EEG recordings in the clinical setting are generally subjected to visual assessment and analysis, which is crucial for the investigation of certain neurophysiological phenomena. However, objective and reproducible investigation of complex EEG signals requires quantitative or computerized EEG analysis. qEGG analysis provides multi-perspective information on the EEG signal such as its frequency components (spectral analysis), dynamic alterations (time analysis) and spatial estimates of cortical sources (space domain analysis) (Fig. 1 and Table 1) [19]. In addition, qEEG provides reliable and quantifiable (numerical) results that can be further utilized in associative and correlative studies [24].

\section{SPECTRAL EEG CHANGES ALONG THE AD CONTINUUM: FREQUENCY DOMAIN ANALYSIS}

The most commonly used qEEG method is frequency domain analysis (Table 1), performed by fast Fourier transform (FFT) spectral analysis (Fig. 1). FFT-based spectral analysis quantifies the amplitude and power of the EEG oscillations averaged throughout a predefined recording period in various frequency bands. The genesis of the characteristic cortical rhythms, divided into conventional slow- and fast-frequency activity, has long been discussed, with thalamocortical circuits and cortex itself as the main 

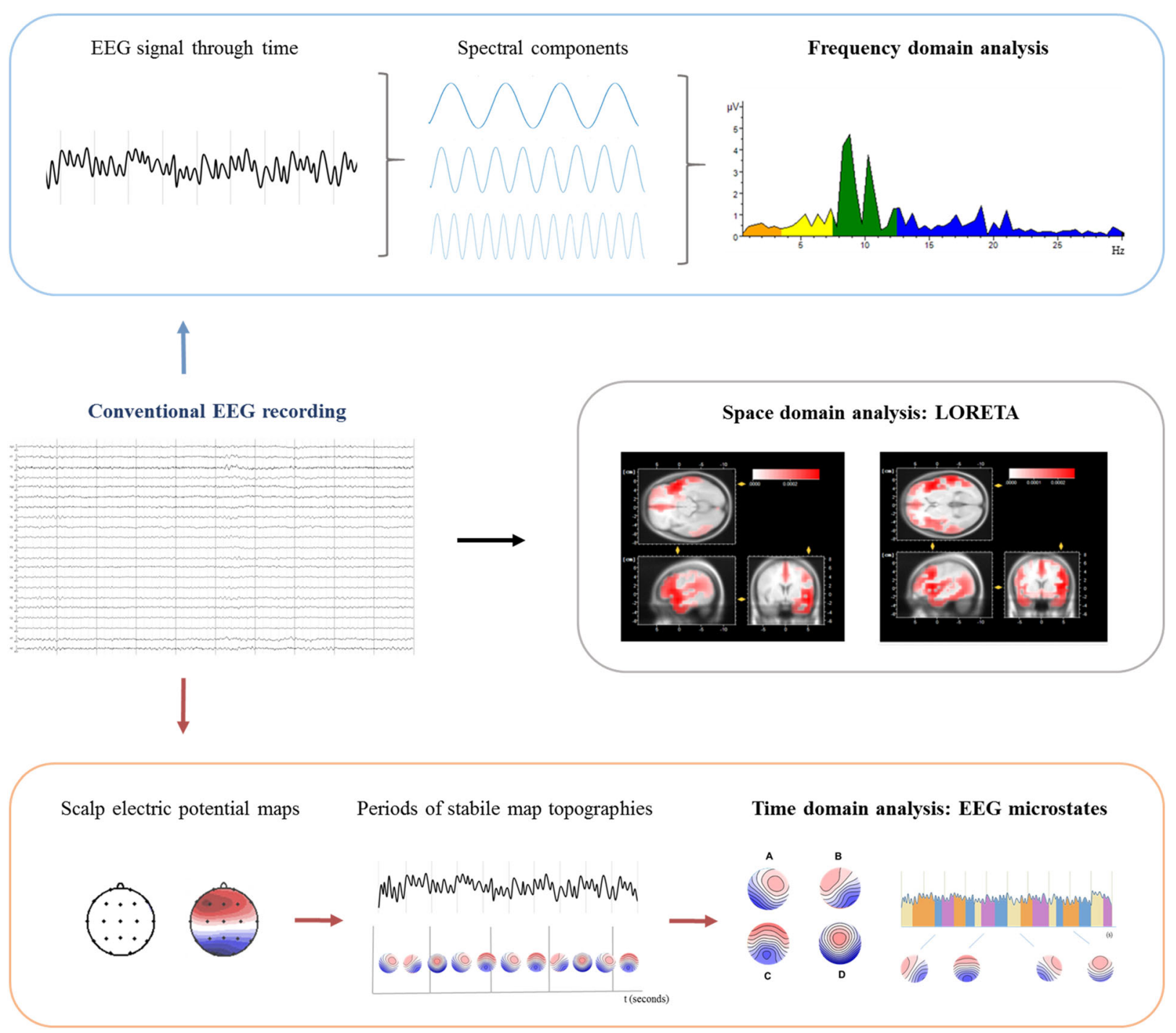

Fig. 1 Quantitative EEG analysis in frequency (FFT spectral analysis; blue square), time (EEG microstate analysis; orange square) and space domains (LORETA = low-resolution brain electromagnetic tomography analysis; gray square)

generators of this phenomenon [82]. Numerous qEEG studies have reported an increase in slowfrequency bands (delta and theta) and a decrease in fast-frequency (alpha and beta) amplitude and power, referred to as generalized EEG slowing in patients along the clinical $\mathrm{AD}$ continuum $[26,27,29,32,49-51,61]$. These findings have been shown to correlate with and be predictive of neuropsychological performance, memory, attention, verbal deficits, frontal lobe function and ability to carry out everyday activities in cognitively impaired individuals [28, 29, 33, 36, 51]. Moreover, these changes seem to develop gradually, that is as an early increase in theta and decrease in beta, followed by a decrease in alpha and late increase in delta power, present in more severe stages of $\mathrm{AD}[25,83]$. A referenced temporal pattern of qEEG changes was substantiated by a prospective qEEG study that demonstrated a decrease in alpha and increase in delta power in $\mathrm{AD}$ patients at the 1-year follow-up compared with baseline [26]. In addition, Jelic et al. and Luckhaus et al. reported that combined alpha and theta power are the best predictors of future cognitive decline in MCI subjects $[38,47]$. 
Table 1 Overview of qEEG studies in the context of dementia research including qEEG analyses in frequency, time and space domains

\begin{tabular}{|c|c|c|c|}
\hline QEEG method & Parameters/classifiers & Study population $(n=$ range $)$ & References \\
\hline \multirow[t]{37}{*}{ Frequency domain analysis } & Power spectral analysis & $\operatorname{SCD}(n=20-210)$ & Coben et al. [25] \\
\hline & Absolute and relative power and amplitude & $\operatorname{MCI}(n=12-230)$ & Soininen et al. [26] \\
\hline & Global field power (GFP) & $\mathrm{AD}(n=14-320)$ & Prichep et al. [27] \\
\hline & Global field synchronization (GFS) & FTD $(n=13-19)$ & Pozzi et al. [28] \\
\hline & Coherence & Mixed $(\mathrm{AD}-\mathrm{VD})(n=24)$ & Jelic et al. [29] \\
\hline & Synchronization likelihood (SL) & DLB/PDD $(n=15-66)$ & Yener et al. [30] \\
\hline & Phase lag index (PLI) & & Chiaramonti et al. [31] \\
\hline & & & Jelic et al. [32] \\
\hline & & & Claus et al. [33] \\
\hline & & & Jelic et al. [34] \\
\hline & & & Rodriguez et al. [35] \\
\hline & & & Nobili et al. [36] \\
\hline & & & Huang et al. [37] \\
\hline & & & Jelic et al. [38] \\
\hline & & & Lehtovirta et al. [39] \\
\hline & & & Adler et al. [40] \\
\hline & & & Lindau et al. $[41]$ \\
\hline & & & Stam et al. [42] \\
\hline & & & Mattia et al. [43] \\
\hline & & & Koenig et al. [44] \\
\hline & & & Park et al. [45] \\
\hline & & & Schreiter Gasser et al. [46] \\
\hline & & & Luckhaus et al. [47] \\
\hline & & & Ommundsen et al. [48] \\
\hline & & & Fonseca et al. [49] \\
\hline & & & Anghinah et al. [50] \\
\hline & & & Kim et al. [51] \\
\hline & & & De Waal et al. [52] \\
\hline & & & Ma et al. [53] \\
\hline & & & Engels et al. [54] \\
\hline & & & Engedal et al. [55] \\
\hline & & & Dauwan et al. [56] \\
\hline & & & Ferreira et al. [57] \\
\hline & & & Gouw et al. [58] \\
\hline & & & Smailovic et al. [59] \\
\hline & & & Schjønning Nielsen et al. [60] \\
\hline & & & Musaeus et al. [61] \\
\hline
\end{tabular}


Table 1 continued

\begin{tabular}{|c|c|c|c|}
\hline QEEG method & Parameters/classifiers & Study population $(n=$ range $)$ & References \\
\hline \multirow[t]{7}{*}{ Time domain analysis } & \multirow[t]{7}{*}{ EEG microstates (topography and parameters) } & $\operatorname{SCD}(n=31)$ & Ihl et al. [62] \\
\hline & & $\operatorname{MCI}(n=38)$ & Dierks et al. [63] \\
\hline & & $\mathrm{AD}(n=8-64)$ & Strik et al. [64] \\
\hline & & FTD $(n=18)$ & Stevens and Kircher [65] \\
\hline & & $\mathrm{SD}(n=8)$ & Nishida et al. [66] \\
\hline & & $\operatorname{DLB}(n=42)$ & Grieder et al. [67] \\
\hline & & & Schumacher et al. [68] \\
\hline \multirow[t]{16}{*}{ Space domain analysis } & Dipole source localization & SMI $(n=1-53)$ & Dierks et al. [69] \\
\hline & \multirow[t]{15}{*}{ LORETA } & $\operatorname{MCI}(n=12-155)$ & Chiaramonti et al. [31] \\
\hline & & $\mathrm{AD}(n=21-193)$ & Huang et al. [37] \\
\hline & & \multirow[t]{13}{*}{ FTD $(n=19-39)$} & Dierks et al. [70] \\
\hline & & & Babiloni et al. [71] \\
\hline & & & Babiloni et al. [72] \\
\hline & & & Gianotti et al. [73] \\
\hline & & & Babiloni et al. [74] \\
\hline & & & Babiloni et al. [75] \\
\hline & & & Nishida et al. [76] \\
\hline & & & Caso et al. [77] \\
\hline & & & Kim et al. [51] \\
\hline & & & Canuet et al. [78] \\
\hline & & & Hatz et al. [79] \\
\hline & & & Babiloni et al. [80] \\
\hline & & & Lizio et al. [81] \\
\hline
\end{tabular}

$A D$ Alzheimer's disease, $D L B$ dementia with Lewy bodies, FTD frontotemporal dementia, LORETA low-resolution brain electromagnetic tomography, $M C I$ mild cognitive impairment, $P D D$ Parkinson's disease dementia, $S D$ semantic dementia, $S C D$ subjective cognitive decline, $S M I$ subjective memory impairment, $V D$ vascular dementia

In contrast to conventional FFT power spectral analysis, recent studies have investigated the single qEEG measure of global field power (GFP). GFP corresponds to the sum of all squared potential differences of all electrodes on the scalp, and therefore represents single and global measures of scalp potential field strength, i.e. generalized EEG amplitude [19]. Huang et al. reported increased delta and theta GFP and decreased alpha GFP in AD patients compared with healthy controls, and decreased alpha and beta GFP in AD compared with MCI patients. In addition, they demonstrated decreased GFP alpha in progressive MCI compared with stable MCI patients [37]. Significant differences in GFP delta, theta and alpha frequency bands have been confirmed in over 600 memory clinic patients diagnosed with SCD, MCI and AD [59], indicating the reproducibility and comparability of reference-independent and simplified measures of EEG power to the conventional multichannel FFT-spectral analysis.

The widespread AD neuropathology, neuronal and synaptic loss, and consequent 
impairment in multiple cognitive domains have motivated the investigation of disturbances in the synchronization of large-scale neural circuits in patients along the AD continuum. EEG coherence has been introduced as a measure of altered brain connectivity and neurophysiological organization $[84,85]$, since it measures the phase consistency between two signals (at two different channels) in each frequency band $[19,85]$. Studies on EEG coherence have shown that $\mathrm{AD}$ patients have decreased coherence in all frequency bands, with the most prominent finding being decreased coherence in the alpha band $[29,32,40,49,50]$. However, the measure of coherence is calculated between the channel pairs only and is contaminated by a volume conduction effect, which implies overall spreading of electrical currents through the biological tissue and can therefore overestimate interdependence between channels [19, 85]. Stam et al. introduced another measure of dynamic interdependence between the two channels (or a set of channels), referred to as synchronization likelihood (SL) [86], which has been shown to correlate with global cognitive status and to decrease across all frequency bands in cognitively impaired patients (MCI and AD) compared with healthy controls [42, 87-89].

The phase lag index (PLI) has been proposed as a new measure of EEG synchrony that overcomes the problem of volume conduction effect [90]. AD patients have been shown to have reduced PLI in alpha and beta bands [54, 90] which correlate with disease severity [54]. However, PLI as such reflects synchronization between pairs of signals and is blind to the true instantaneous interactions that might constitute a substantial amount of connectivity between brain regions. Koenig et al. introduced a method that reduces multichannel EEG analysis to the single global measure of brain functional connectivity across frequency bands. Global field synchronization (GFS) is therefore a reference-free method that measures the instantaneous phase-locked neural activity across the whole scalp, oblivious to differences in activity of a single or several sources oscillating at the same time, as it includes all electrodes simultaneously and makes no assumption about the location of the sources of brain activity [91]. Decreased GFS in fast frequencies (alpha and beta) with the more severe stage of cognitive impairment has been reported in three large databases comprising healthy controls and memory clinic patients [44, 59]. Moreover, Park et al. and Ma et al. highlighted that GFS alterations correlate with cognitive status in AD patients, assessed by the MiniMental State Examination (MMSE), Montreal Cognitive Assessment (MoCA) and Clinical Dementia Rating (CDR) Scale [45, 53].

Widespread disturbances in neural signaling in patients with preclinical and clinical AD have been confirmed with multiple qEEG measures of brain functional connectivity, suggesting qEEG as a valuable method for investigation of $\mathrm{AD}$ as a "global disconnection syndrome" $[44,92]$.

\section{BRAIN NETWORK DYNAMICS IN AD: TIME DOMAIN ANALYSIS}

Resting-state qEEG frequency domain analysis revealed $\mathrm{AD}$-associated disturbances in brain synchronous activity in physiologically meaningful frequency ranges. However, when it comes to the investigation of neurocognitive networks, another aspect of interest involves the investigation of their intrinsic dynamic properties that might disintegrate in patients with impaired higher cortical functions, such as in patients along the $\mathrm{AD}$ continuum. Temporal organization of neuronal networks can be analyzed by investigating the momentary brain states with a high temporal resolution, in the millisecond range, allowed by EEG [19]. This led to the discovery of EEG microstates-periods of stable topographies of electric fields that are thought to reflect all momentary active neural networks [93]. These topographies of electric fields represent 2-D scalp maps of EEG electric potential values recorded at all electrode sites at a given moment in time. Spontaneous restingstate EEG recording can therefore be presented as a time series of alternating momentary brain states, i.e. functional microstates (Fig. 1). Microstates have several remarkable properties: their duration is compatible with the resolution of human information processing (60-120 ms), 
they transition sharply from one to another topographical configuration, and only a limited number of microstate topographies can explain a great part of the variance in the resting-state EEG data across different subjects [93-95]. Most of the resting-state EEG microstate studies report four reproducible and analogous clusters of microstate topographies, referred to as maps A, B, C and D [94].

Several studies have reported changes in microstate dynamics and/or topographies in patients with dementia. Ihl et al. showed that $\mathrm{AD}$ patients have longer microstate duration than healthy controls [62]. On the other hand, three independent studies reported decreased EEG microstate duration, two of which showed anteriorization of the electric fields and correlation of microstate alterations with cognitive performance in AD patients [63-65]. However, a study that distinguished four conventional microstate maps by employing more advanced spatial cluster analysis revealed an increase in the duration of asymmetrical microstate maps (A and B) and a decrease in the duration of symmetrical maps (C and D) in patients with the more severe stage of cognitive impairment [96]. Conversely, Nishida et al. and Grieder et al. reported no changes in microstate dynamics or topographies; however, they included patients with other types of dementia and only a small number of patients with $\mathrm{AD}[66,67]$. More recently, Schumacher et al. showed that microstate topographies are indeed altered in $\mathrm{AD}$ patients for all microstate classes compared with controls and patients with Lewy body dementia [68].

Studies employing different functional imaging modalities have already reported disturbances of large-scale brain networks during rest in cognitively impaired patients [97]. Investigation of EEG microstate topographies and dynamics might therefore be a valuable tool for detecting fine disarrangements in activation and organization of large-scale restingstate networks in AD patients [93, 94]. Even though microstate analysis lacks straightforward topographical interpretation, its distinct temporal organization and across-subject reproducible topographical representation makes it a plausible marker candidate for future validation studies of brain functional impairment.

\section{MAPPING BRAIN (DYS)FUNCTION USING QEEG: SPACE DOMAIN ANALYSIS}

Some of the first attempts to directly assess topographical correlates of EEG-recorded brain activity included the dipole source localization method. It involved "fitting" of a single dipole in the three-dimensional (3-D) coordinating system that depicts the corresponding center of gravity and strength of the intracerebral activity [98]. Using the referenced technique, several studies have shown more anteriorly located centers of gravity of alpha and beta activity in AD patients compared with healthy controls and MCI subjects. The general anteriorization of fast-frequency activity was hypothesized to be associated with the early and more severe neuropathology in the posterior brain areas in patients along the $\mathrm{AD}$ continuum. In addition, the degree of shift was reported to be sensitive to disease activity and progression, as it correlated with the severity of cognitive impairment and was predictive of the development of $\mathrm{AD}$ in MCI patients [31, 37, 69]. Dipole source localization is a simple and user-friendly estimator of the electric gravity center, but does not portray a realistic location of the EEG generators, for two reasons: it calculates a single locus of activity, while the exact number of dipoles to be optimally fitted remains unknown [19].

Mapping the electrical generators in the brain that give rise to the electric field topographies at the level of the scalp is enabled by mathematical calculations of the EEG inverse solution. Low-resolution electromagnetic tomography (LORETA) is a functional neuroimaging method that estimates cortical sources of brain electrical activity in a 3-D human head model (Fig. 1) [99]. Decreased activity in parieto-occipital alpha sources and widespread increases in activity in delta and theta bands have been repeatedly reported in $\mathrm{AD}$ patients compared with healthy controls [51, 72, 73, 78, 80, 89]. Babiloni et al. showed that some of the referred disturbances in 
cortical EEG rhythms occur already in subjects with memory complaints (SMC) and MCI patients, supporting the hypothesis of brain functional disturbances already in the pre-dementia stages of the disease [74]. In addition, introduced studies have shown that cortical sources of delta, theta and alpha activity correlate with neuropsychological test scores and are sensitive to disease progression, suggesting clinical implication for EEG-based imaging techniques in cognitively impaired individuals $[51,72,73,75,80]$. The LORETA method can also be utilized for regional assessment of brain functional connectivity. Canuet et al. reported decreased lagged phase synchronization between the medial frontal/parietal region and the left temporal and bilateral inferior parietal cortex in the alpha 2 frequency band and the most prominent increase in synchronization of low-frequency activity of the temporal lobe in 125 AD patients [78]. EEG neuroimaging methods can therefore be used for topographical investigation of resting-state disruptions of cortical activity and functional connectivity in $\mathrm{AD}$ patients.

\section{BIOLOGICAL VALIDITY OF QEEG MEASURES: WHAT DOES QEEG ADD?}

Studies employing multi-perspective qEEG analyses have demonstrated an association between qEEG measures and the cognitive status, disease activity and progression in subjects along the $\mathrm{AD}$ continuum; however, biological and clinical validation of the referred markers requires further investigation of their relationship to disease-specific neuropathology.

Conventional cerebrospinal fluid (CSF) markers of $\mathrm{AD}$ include decreased $\mathrm{A} \beta 42$ and increased total tau (t-tau) and phosphorylated tau (p-tau) protein levels as a result of amyloid and tau accumulation and pathology in the brain of AD patients [100]. The referred biomarker pattern has demonstrated good sensitivity, specificity and predictive value for future cognitive deterioration [101]. Jelic et al. showed that CSF tau levels correlate with the ratio of alpha and delta global power in AD patients.
Interestingly, this revealed a negative correlation between EEG slowing and CSF tau levels; however, the study involved a rather small population and only $14 \mathrm{AD}$ patients [34]. A retrospective study including over 600 memory clinic patients diagnosed with SCD, MCI and $\mathrm{AD}$ reported a significant negative correlation between CSF A $\beta 42$ levels and global power in slow and CSF p- and t-tau levels and global power in fast frequencies [59]. It suggested the pattern of AD-related changes in qEEG parameters: amyloid pathology might mediate slowfrequency disturbances through cholinergic dysfunction, while tau pathology resembles neuronal loss and degeneration that might particularly affect fast frequencies, presumably generated and propagated in the cortex itself. On the other hand, CSF biomarkers were associated with decreased global synchronization in fast frequencies only [59], which has already been shown to correlate with the degree of cognitive decline $[45,53,102]$. This notion was substantiated in a study by Babiloni et al., who demonstrated a correlation of the level of hippocampal and occipital gray matter volume and density with cortical alpha activity, estimated by LORETA imaging, in MCI and AD patients [103-105]. Conversely, Mattia et al. reported a lack of association between EEG power spectra and index of brain atrophy in a small-scale study, although they did not employ source imaging techniques. Yet the same study demonstrated a correlation between alpha and theta power and total level of brain hypoperfusion assessed by perfusion MRI, indicating a relationship between neurophysiological and hemodynamic changes in AD patients [43].

The topography of abnormal synaptic activity can be further assessed using FDG-PET to analyze brain glucose metabolism [106]. Many studies have shown that decreased glucose metabolism in temporoparietal regions is an early and consistent finding in $\mathrm{AD}$ and cognitively deteriorating MCI patients [107-110]. When it comes to the correlative FDG-PET-EEG studies, both Dierks et al. and Babiloni et al. reported an association between topographical estimates of EEG generators and patterns of brain glucose metabolism, employing dipole 
and LORETA source localization techniques $[70,111]$.

The effect of the apolipoprotein $\varepsilon 4(\mathrm{apoE} \varepsilon 4)$ genotype, a risk factor for the disease [112], on neurophysiological disturbances in AD patients is still open to discussion. Jelic. et al. reported an association between apoE $\varepsilon 4$ and reduced alpha coherence in $\mathrm{AD}$ patients [32], while Lehtovirta et al. described more pronounced slow EEG activity in apoE $\varepsilon 4$ carriers [39]. Conversely, a more recent large-scale study demonstrated that $\mathrm{AD}$ apoE $\varepsilon 4$ noncarriers exhibited more severe EEG slowing than apoE $\varepsilon 4$ carriers [52]. Topographical EEG analysis in a study by Canuet et al. reported an association between the apoE $\varepsilon 4$ allele and decreased alpha activity in the left inferior parietal and temporooccipital cortex and reduced alpha connectivity in the frontal and temporoparietal regions in $\mathrm{AD}$ patients [78]. While the relationship between apoE $\varepsilon 4$ and the molecular neuropathology in $\mathrm{AD}$ patients has been thoroughly described [113-115], an unambiguous association with the disturbances in brain function remains to be demonstrated in future studies.

qEEG markers in the frequency and space domains have been shown to correlate with ADassociated molecular and neuroimaging markers; however, most of the latter will fail to reach pathological thresholds in the early, pre-dementia stages of the disease. Moreover, subjects in preclinical and early clinical stages of the disease show discordance between the severity of clinical symptoms and conventional biomarker abnormalities, in addition to considerable biological and clinical heterogeneity. This can be explained, at least in part, by the different levels of cognitive reserve in these patient groups and a lack of diagnostic markers that would directly indicate disturbances in brain function. Several studies have already shown that qEEG complements and improves the currently established diagnostic workup of patients along the $\mathrm{AD}$ continuum $[57,116,117]$. qEEG may therefore be a valuable add-on in dementia assessment, as an early marker of brain synaptic (functional) disturbances due to the AD molecular neuropathology.

\section{QEEG IN DIFFERENTIAL DIAGNOSIS OF DEMENTIA}

There is growing evidence that a considerable number of cognitively impaired patients with clinical presentation of AD have pathologically mixed or other types of dementia [118-121], some of them being just recently described [122]. Therefore, candidate markers of AD would ideally reflect both the clinical stage of the disease and the underlying disease-specific brain pathology.

It has been long known that EEG signals exhibit high interindividual variability [123], thus emphasizing the need for quantitative analyses that might provide a more objective approach to neurophysiological phenotyping. In addition, measures of EEG variability as a function of brain (dis)organization and inflexibility have appeared as a novel subject of interest [124-126]. Lehmann et al. reported that a set of qEEG features, including EEG measures of amplitude, power and synchronization, have overall sensitivity of up to $85 \%$ and $89 \%$ and specificity of $78 \%$ and $88 \%$ in differentiating mild and moderate $\mathrm{AD}$, respectively, from healthy controls [127]. Many EEG studies have shown a plausible classification rate of qEEG measures in discriminating both $\mathrm{MCI}$ and $\mathrm{AD}$ patients from healthy controls $[40,55,57,81,128]$.

When it comes to the neurophysiological potential to distinguish AD from other types of dementia, Lindau et al. demonstrated that patients with frontotemporal dementia (FTD) have a more severe decrease in fast-frequency and lack of increase in slow-frequency power compared with $\mathrm{AD}$ patients $[41,129]$. In addition, FTD patients exhibit decreased global field synchronization in all frequency bands relative to both healthy controls and AD patients, suggesting GFS as a valuable differential diagnostic tool [129]. An EEG source localization study further unveiled the topographical pattern of observed changes: decreased alpha 1 activity in the orbitofrontal and temporal lobes in FTD patients versus controls, a widespread increase in delta activity in $\mathrm{AD}$ patients versus controls, and a more pronounced decrease in beta 1 
activity in the parietal lobe and sensorimotor area in AD versus FTD patients [76]. EEG analysis in the time domain additionally revealed shorter microstate duration of asymmetric class $\mathrm{C}$ in FTD patients, indicating the sensitivity of microstate parameters to frontal lobe dysfunction [66].

In contrast, patients diagnosed with mixed dementia, i.e. vascular and Alzheimer's dementia, seem to exhibit a more pronounced increase in slow-frequency power and a lack of decrease in fast-frequency power compared with $\mathrm{AD}$ patients [46], indicating an opposite qEEG power spectral pattern to that observed in FTD patients. This notion was substantiated by the multicenter EEG LORETA study by Babiloni et al. that showed a distributed increase in theta activity in vascular dementia relative to healthy controls and AD patients [130].

One of the most common forms of dementia, following Alzheimer's disease, is dementia with Lewy bodies (DLB) [131]. Prominent EEG slowing in the posterior regions, more severe than that observed in patients along the $\mathrm{AD}$ continuum, is one of the main EEG findings in patients with DLB [132-134]. These EEG changes occur early during the disease course and correlate well with the clinically evident cognitive fluctuations [135]. In addition, disturbances in resting-state network connectivity and brain network dynamics, evidenced by EEG microstate and functional connectivity studies, have been repeatedly reported in DLB patients $[68,132,136]$. According to the latest DLB Consortium consensus report, EEG should be included as a supportive DLB diagnostic biomarker [135], as EEG features seem to exhibit particularly high potential in differentiating DLB from $\mathrm{AD}$ and other types of dementia [55-57, 126, 137].

Most of the studies that investigated the classification potential of qEEG methods in the context of dementia were based on group-level analyses. It is of interest for future validation studies to explore and validate qEEG as a diagnostic tool on the single-subject level, necessary for future clinical implementation.

\section{CONCLUSIONS}

There is an urgent need for novel functional biomarkers of $\mathrm{AD}$ for use in both clinical settings and drug trials. EEG is a noninvasive, lowcost and widely available diagnostic method that directly reflects synaptic activity, which is significantly affected early in the course of AD. In addition, applying objective and multi-perspective quantitative EEG analyses enables the investigation of physiologically meaningful frequency, time and space components of EEG signals. Since a number of prospective studies have reported promising diagnostic and prognostic potential for qEEG measures, there is a need to confirm a concordance of qEEG findings with the amyloid PET status and postmortem disease-specific neuropathological changes in patients with preclinical and clinical $\mathrm{AD}$. In addition, high between- and state-dependent within-subject variability in EEG signals suggests a combination, rather than just a single measure, of qEEG parameters as a plausible marker of $\mathrm{AD}$ dementia. Hence, future large-scale longitudinal studies that integrate analysis in different but complementary domains with novel and advanced topographical and temporal properties might help elucidate reliable and robust qEEG measures that could be utilized at the individual-level dementia assessment.

\section{ACKNOWLEDGEMENTS}

Funding. No funding or sponsorship was received for this study or publication of this article.

Authorship. All named authors meet the International Committee of Medical Journal Editors (ICMJE) criteria for authorship for this article, take responsibility for the integrity of the work as a whole, and have given their approval for this version to be published.

Disclosures. Una Smailovic and Vesna Jelic have nothing to disclose. 
Compliance with Ethics Guidelines. This article is based on previously conducted studies and does not contain any studies with human participants or animals performed by any of the authors.

Open Access. This article is distributed under the terms of the Creative Commons Attribution-NonCommercial 4.0 International License (http://creativecommons.org/licenses/ by-nc/4.0/), which permits any noncommercial use, distribution, and reproduction in any medium, provided you give appropriate credit to the original author(s) and the source, provide a link to the Creative Commons license, and indicate if changes were made.

\section{REFERENCES}

1. Mehta D, Jackson R, Paul G, Shi J, Sabbagh M. Why do trials for Alzheimer's disease drugs keep failing? A discontinued drug perspective for 2010-2015. Expert Opin Investig Drugs. 2017;26(6):735-9. https://doi.org/10.1080/13543784.2017.1323868.

2. Mattsson N, Carrillo MC, Dean RA, Devous MD Sr, Nikolcheva T, Pesini P, et al. Revolutionizing Alzheimer's disease and clinical trials through biomarkers. Alzheimers Dement (Amst). 2015;1(4): 412-9. https://doi.org/10.1016/j.dadm.2015.09. 001.

3. Stern Y. Cognitive reserve in ageing and Alzheimer's disease. Lancet Neurol. 2012;11(11):1006-12. https://doi.org/10.1016/S1474-4422(12)70191-6.

4. Jessen F, Wiese B, Bachmann C, Eifflaender-Gorfer $\mathrm{S}$, Haller F, Kolsch $\mathrm{H}$, et al. Prediction of dementia by subjective memory impairment: effects of severity and temporal association with cognitive impairment. Arch Gen Psychiatry. 2010;67(4): 414-22. https://doi.org/10.1001/archgenpsychiatry. 2010.30.

5. Jessen F, Amariglio RE, Boxtel M, Breteler M, Ceccaldi M, Chételat G. A conceptual framework for research on subjective cognitive decline in preclinical Alzheimer's disease. Alzheimers Dement. 2014. https://doi.org/10.1016/j.jalz.2014.01.001.

6. Hampel H, Frank R, Broich K, Teipel SJ, Katz RG, Hardy J, et al. Biomarkers for Alzheimer's disease: academic, industry and regulatory perspectives. Nat Rev Drug Discov. 2010;9(7):560-74. https://doi.org/ $10.1038 / \mathrm{nrd} 3115$
7. Hippius H, Neundörfer G. The discovery of Alzheimer's disease. Dialogues Clin Neurosci. 2003;5(1): 101-8.

8. Scheff SW, Price DA, Schmitt FA, DeKosky ST, Mufson EJ. Synaptic alterations in CA1 in mild Alzheimer disease and mild cognitive impairment. Neurology. 2007;68(18):1501-8. https://doi.org/10. 1212/01.wnl.0000260698.46517.8f.

9. Scheff SW, Price DA, Schmitt FA, Mufson EJ. Hippocampal synaptic loss in early Alzheimer's disease and mild cognitive impairment. Neurobiol Aging. 2006;27(10):1372-84. https://doi.org/10.1016/j. neurobiolaging.2005.09.012.

10. Masliah E, Mallory M, Alford M, DeTeresa R, Hansen LA, McKeel DW Jr, et al. Altered expression of synaptic proteins occurs early during progression of Alzheimer's disease. Neurology. 2001;56(1):127-9.

11. Terry RD, Masliah E, Salmon DP, Butters N, DeTeresa R, Hill R, et al. Physical basis of cognitive alterations in Alzheimer's disease: synapse loss is the major correlate of cognitive impairment. Ann Neurol. 1991;30(4):572-80. https://doi.org/10. 1002/ana.410300410.

12. Selkoe DJ, Hardy J. The amyloid hypothesis of Alzheimer's disease at 25 years. EMBO Mol Med. 2016;8(6):595-608. https://doi.org/10.15252/emmm. 201606210.

13. Shankar GM, Li S, Mehta TH, Garcia-Munoz A, Shepardson NE, Smith I, et al. Amyloid-beta protein dimers isolated directly from Alzheimer's brains impair synaptic plasticity and memory. Nat Med. 2008;14(8): 837-42. https://doi.org/10.1038/nm1782.

14. Jin M, Shepardson N, Yang T, Chen G, Walsh D, Selkoe DJ. Soluble amyloid $\beta$-protein dimers isolated from Alzheimer cortex directly induce Tau hyperphosphorylation and neuritic degeneration. Proc Natl Acad Sci USA. 2011;108(14):5819-24. https://doi.org/10.1073/pnas.1017033108.

15. Tomiyama $\mathrm{T}$, Matsuyama $\mathrm{S}$, Iso $\mathrm{H}$, Umeda $\mathrm{T}$, Takuma H, Ohnishi K, et al. A mouse model of amyloid beta oligomers: their contribution to synaptic alteration, abnormal tau phosphorylation, glial activation, and neuronal loss in vivo. J Neurosci. 2010;30(14):4845-56. https://doi.org/10. 1523/jneurosci.5825-09.2010.

16. Ferretti MT, Bruno MA, Ducatenzeiler A, Klein WL, Cuello AC. Intracellular Abeta-oligomers and early inflammation in a model of Alzheimer's disease. Neurobiol Aging. 2012;33(7):1329-42. https://doi. org/10.1016/j.neurobiolaging.2011.01.007.

17. Davies CA, Mann DM, Sumpter PQ, Yates PO. A quantitative morphometric analysis of the neuronal 
and synaptic content of the frontal and temporal cortex in patients with Alzheimer's disease. J Neurol Sci. 1987;78(2):151-64.

18. DeKosky ST, Scheff SW. Synapse loss in frontal cortex biopsies in Alzheimer's disease: correlation with cognitive severity. Ann Neurol. 1990;27(5): 457-64. https://doi.org/10.1002/ana.410270502.

19. Michel CM. Electrical neuroimaging. Cambridge medicine. Cambridge: Cambridge University Press; 2009.

20. Sato S, Balish M, Muratore R. Principles of magnetoencephalography. J Clin Neurophysiol. 1991;8(2): 144-56.

21. Motta C, Di Lorenzo F, Ponzo V, Pellicciari MC, Bonni S, Picazio S, et al. Transcranial magnetic stimulation predicts cognitive decline in patients with Alzheimer's disease. J Neurol Neurosurg Psychiatry. 2018;89(12):1237-42. https://doi.org/10. 1136/jnnp-2017-317879.

22. Heurling K, Ashton NJ, Leuzy A, Zimmer ER, Blennow $\mathrm{K}$, Zetterberg $\mathrm{H}$, et al. Synaptic vesicle protein $2 \mathrm{~A}$ as a potential biomarker in synaptopathies. Mol Cell Neurosci. 2019;97:34-42. https://doi.org/10. 1016/j.mcn.2019.02.001.

23. Robinson JL, Molina-Porcel L, Corrada MM, Raible K, Lee EB, Lee VMY, et al. Perforant path synaptic loss correlates with cognitive impairment and Alzheimer's disease in the oldest-old. Brain. 2014;137(9):2578-87. https://doi.org/10.1093/ brain/awu190.

24. Nuwer M. Assessment of digital EEG, quantitative EEG, and EEG brain mapping: report of the American Academy of Neurology and the American Clinical Neurophysiology Society. Neurology. 1997;49(1):277. https://doi.org/10.1212/WNL.49.1. 277.

25. Coben LA, Danziger W, Storandt M. A longitudinal EEG study of mild senile dementia of Alzheimer type: changes at 1 year and at 2.5 years. Electroencephalogr Clin Neurophysiol. 1985;61(2):101-12.

26. Soininen HPJ, Paakkonen A, Koivisto E, Riekkinen PJ. Changes in absolute power values of EEG spectra in the follow-up of Alzheimer's disease. Acta Neurol Scand. 1991;83:133-6.

27. Prichep LS, John ER, Ferris SH, Reisberg B, Almas M, Alper K, et al. Quantitative EEG correlates of cognitive deterioration in the elderly. Neurobiol Aging. 1994;15(1):85-90.

28. Pozzi D, Petracchi M, Sabe L, Golimstock A, Garcia H, Starkstein S. Quantified electroencephalographic correlates of neuropsychological deficits in
Alzheimer's disease. J Neuropsychiatry Clin Neurosci. 1995;7(1):61-7. https://doi.org/10.1176/jnp. 7.1.61.

29. Jelic V, Shigeta M, Julin P, Almkvist O, Winblad B, Wahlund LO. Quantitative electroencephalography power and coherence in Alzheimer's disease and mild cognitive impairment. Dementia. 1996;7(6): 314-23.

30. Yener GG, Leuchter AF, Jenden D, Read SL, Cummings JL, Miller BL. Quantitative EEG in frontotemporal dementia. Clin Electroencephalogr. 1996;27(2):61-8.

31. Chiaramonti R, Muscas GC, Paganini M, Muller TJ, Fallgatter AJ, Versari A, et al. Correlations of topographical EEG features with clinical severity in mild and moderate dementia of Alzheimer type. Neuropsychobiology. 1997;36(3):153-8. https://doi. org/10.1159/000119375.

32. Jelic V, Julin P, Shigeta M, Nordberg A, Lannfelt L, Winblad B, et al. Apolipoprotein E epsilon4 allele decreases functional connectivity in Alzheimer's disease as measured by EEG coherence. J Neurol Neurosurg Psychiatry. 1997;63(1):59-65.

33. Claus JJ, Kwa VI, Teunisse S, Walstra GJ, van Gool WA, Koelman JH, et al. Slowing on quantitative spectral EEG is a marker for rate of subsequent cognitive and functional decline in early Alzheimer disease. Alzheimer Dis Assoc Disord. 1998;12(3): 167-74.

34. Jelic V, Blomberg M, Dierks T, Basun H, Shigeta M, Julin $P$, et al. EEG slowing and cerebrospinal fluid tau levels in patients with cognitive decline. NeuroReport. 1998;9(1):157-60.

35. Rodriguez G, Copello F, Vitali P, Perego G, Nobili F. EEG spectral profile to stage Alzheimer's disease. Clin Neurophysiol. 1999;110(10):1831-7.

36. Nobili F, Copello F, Vitali P, Prastaro T, Carozzo S, Perego G, et al. Timing of disease progression by quantitative EEG in Alzheimer' s patients. J Clin Neurophysiol. 1999;16(6):566-73.

37. Huang C, Wahlund L, Dierks T, Julin P, Winblad B, Jelic V. Discrimination of Alzheimer's disease and mild cognitive impairment by equivalent EEG sources: a cross-sectional and longitudinal study. Clin Neurophysiol. 2000;111(11):1961-7.

38. Jelic V, Johansson SE, Almkvist O, Shigeta M, Julin $\mathrm{P}$, Nordberg A, et al. Quantitative electroencephalography in mild cognitive impairment: longitudinal changes and possible prediction of Alzheimer's disease. Neurobiol Aging. 2000;21(4): 533-40. 
39. Lehtovirta M, Partanen J, Könönen M, Hiltunen J, Helisalmi S, Hartikainen P, et al. A Longitudinal quantitative EEG study of Alzheimer's disease: relation to apolipoprotein $\mathrm{E}$ polymorphism. Dement Geriatr Cogn Disord. 2000;11(1):29-35.

40. Adler G, Brassen S, Jajcevic A. EEG coherence in Alzheimer's dementia. J Neural Transm (Vienna). 2003;110(9):1051-8. https://doi.org/10.1007/s00702003-0024-8.

41. Lindau M, Jelic V, Johansson SE, Andersen C, Wahlund LO, Almkvist O. Quantitative EEG abnormalities and cognitive dysfunctions in frontotemporal dementia and Alzheimer's disease. Dement Geriatr Cogn Disord. 2003;15(2):106-14. https://doi.org/10.1159/000067973.

42. Stam CJ, Van Der Made Y, Pijnenburg YAL, Scheltens $P$. EEG synchronization in mild cognitive impairment and Alzheimer's disease. Acta Neurol Scand. 2003;108(2):90-6. https://doi.org/10.1034/j. 1600-0404.2003.02067.x.

43. Mattia D, Babiloni F, Romigi A, Cincotti F, Bianchi L, Sperli F, et al. Quantitative EEG and dynamic susceptibility contrast MRI in Alzheimer's disease: a correlative study. Clin Neurophysiol. 2003;114(7): 1210-6.

44. Koenig T, Prichep L, Dierks T, Hubl D, Wahlund LO, John ER, et al. Decreased EEG synchronization in Alzheimer's disease and mild cognitive impairment. Neurobiol Aging. 2005;26(2):165-71. https://doi. org/10.1016/j.neurobiolaging.2004.03.008.

45. Park YM, Che HJ, Im CH, Jung HT, Bae SM, Lee SH. Decreased EEG synchronization and its correlation with symptom severity in Alzheimer's disease. Neurosci Res. 2008;62(2):112-7. https://doi.org/10. 1016/j.neures.2008.06.009.

46. Schreiter Gasser U, Rousson V, Hentschel F, Sattel $\mathrm{H}$, Gasser T. Alzheimer disease versus mixed dementias: an EEG perspective. Clin Neurophysiol. 2008;119(10):2255-9. https://doi.org/10.1016/j.clin ph.2008.07.216.

47. Luckhaus C, Grass-Kapanke B, Blaeser I, Ihl R, Supprian $T$, Winterer $G$, et al. Quantitative EEG in progressing vs stable mild cognitive impairment (MCI): results of a 1-year follow-up study. Int J Geriatr Psychiatry. 2008;23(11):1148-55. https:// doi.org/10.1002/gps.2042.

48. Ommundsen N, Engedal K, Oksengard AR. Validity of the quantitative EEG statistical pattern recognition method in diagnosing Alzheimer's disease. Dement Geriatr Cogn Disord. 2011;31(3):195-201. https://doi.org/10.1159/000324878.
49. Fonseca LC, Tedrus GM, Prandi LR, Andrade AC. Quantitative electroencephalography power and coherence measurements in the diagnosis of mild and moderate Alzheimer's disease. Arq Neuropsiquiatr. 2011;69(2b):297-303.

50. Anghinah R, Kanda PA, Lopes HF, Basile LF, Machado S, Ribeiro P, et al. Alzheimer's disease qEEG: spectral analysis versus coherence: which is the best measurement? Arq Neuro-Psiquiatr. 2011;69(6):871-4.

51. Kim JS, Lee SH, Park G, Kim S, Bae SM, Kim DW, et al. Clinical implications of quantitative electroencephalography and current source density in patients with Alzheimer's disease. Brain Topogr. 2012;25(4):461-74. https://doi.org/10.1007/s10548012-0234-1.

52. de Waal H, Stam CJ, de Haan W, van Straaten EC, Blankenstein MA, Scheltens P, et al. Alzheimer's disease patients not carrying the apolipoprotein $\mathrm{E}$ epsilon 4 allele show more severe slowing of oscillatory brain activity. Neurobiol Aging. 2013;34(9): 2158-63. https://doi.org/10.1016/j.neurobiolaging. 2013.03.007.

53. Ma CC, Liu AJ, Liu AH, Zhou XY, Zhou SN. Electroencephalogram global field synchronization analysis: a new method for assessing the progress of cognitive decline in Alzheimer's disease. Clin EEG Neurosci. 2014;45(2):98-103. https://doi.org/10. $1177 / 1550059413489669$.

54. Engels MM, Stam CJ, van der Flier WM, Scheltens P, de Waal $\mathrm{H}$, van Straaten EC. Declining functional connectivity and changing hub locations in Alzheimer's disease: an EEG study. BMC Neurol. 2015;15:145. https://doi.org/10.1186/s12883-0150400-7.

55. Engedal K, Snaedal J, Hoegh P, Jelic V, Bo Andersen B, Naik M, et al. Quantitative EEG applying the statistical recognition pattern method: a useful tool in dementia diagnostic workup. Dement Geriatr Cogn Disord. 2015;40(1-2):1-12. https://doi.org/ $10.1159 / 000381016$.

56. Dauwan M, van der Zande JJ, van Dellen E, Sommer IE, Scheltens P, Lemstra AW, et al. Random forest to differentiate dementia with Lewy bodies from Alzheimer's disease. Alzheimers Dement (Amst). 2016;4:99-106. https://doi.org/10.1016/j.dadm.2016. 07.003 .

57. Ferreira D, Jelic V, Cavallin L, Oeksengaard AR, Snaedal J, Hogh P, et al. Electroencephalography is a good complement to currently established dementia biomarkers. Dement Geriatr Cogn Disord. 2016;42(1-2):80-92. https://doi.org/10.1159/00044 8394. 
58. Gouw AA, Alsema AM, Tijms BM, Borta A, Scheltens $\mathrm{P}$, Stam CJ, et al. EEG spectral analysis as a putative early prognostic biomarker in nondemented, amyloid positive subjects. Neurobiol Aging. 2017;57: 133-42. https://doi.org/10.1016/j.neurobiolaging. 2017.05.017.

59. Smailovic U, Koenig T, Kareholt I, Andersson T, Kramberger MG, Winblad B, et al. Quantitative EEG power and synchronization correlate with Alzheimer's disease CSF biomarkers. Neurobiol Aging. 2018;63:88-95. https://doi.org/10.1016/j.neurobio laging.2017.11.005.

60. Schjønning Nielsen M, Simonsen AH, Siersma V, Engedal K, Jelic V, Andersen BB, et al. Quantitative electroencephalography analyzed by statistical pattern recognition as a diagnostic and prognostic tool in mild cognitive impairment: results from a nordic multicenter cohort study. Dementia Geriatr Cogn Disord Extra. 2018;8(3):426-38. https://doi.org/10. $1159 / 000490788$.

61. Musaeus CS, Engedal K, Hogh P, Jelic V, Morup M, Naik M, et al. EEG theta power is an early marker of cognitive decline in dementia due to Alzheimer's disease. J Alzheimers Dis. 2018;64(4):1359-71. https://doi.org/10.3233/jad-180300.

62. Ihl R, Dierks T, Froelich L, Martin EM, Maurer K. Segmentation of the spontaneous EEG in dementia of the Alzheimer type. Neuropsychobiology. 1993;27(4):231-6. https://doi.org/10.1159/000118 986.

63. Dierks T, Jelic V, Julin P, Maurer K, Wahlund LO, Almkvist O, et al. EEG-microstates in mild memory impairment and Alzheimer's disease: possible association with disturbed information processing. J Neural Transm (Vienna). 1997;104(4-5):483-95. https://doi.org/10.1007/BF01277666.

64. Strik WK, Chiaramonti R, Muscas GC, Paganini M, Mueller TJ, Fallgatter AJ, et al. Decreased EEG microstate duration and anteriorisation of the brain electrical fields in mild and moderate dementia of the Alzheimer type. Psychiatry Res. 1997;75(3): 183-91.

65. Stevens A, Kircher T. Cognitive decline unlike normal aging is associated with alterations of EEG temporo-spatial characteristics. Eur Arch Psychiatry Clin Neurosci. 1998;248(5):259-66.

66. Nishida K, Morishima Y, Yoshimura M, Isotani T, Irisawa $\mathrm{S}$, Jann $\mathrm{K}$, et al. EEG microstates associated with salience and frontoparietal networks in frontotemporal dementia, schizophrenia and Alzheimer's disease. Clin Neurophysiol. 2013;124(6): 1106-14. https://doi.org/10.1016/j.clinph.2013.01. 005.
67. Grieder M, Koenig T, Kinoshita T, Utsunomiya K, Wahlund LO, Dierks T, et al. Discovering EEG resting state alterations of semantic dementia. Clin Neurophysiol. 2016;127(5):2175-81. https://doi. org/10.1016/j.clinph.2016.01.025.

68. Schumacher J, Peraza LR, Firbank M, Thomas AJ, Kaiser M, Gallagher P, et al. Dysfunctional brain dynamics and their origin in Lewy body dementia. Brain. 2019. https://doi.org/10.1093/brain/awz069.

69. Dierks T, Ihl R, Frolich L, Maurer K. Dementia of the Alzheimer type: effects on the spontaneous EEG described by dipole sources. Psychiatry Res. 1993;50(3):151-62.

70. Dierks T, Jelic V, Pascual-Marqui RD, Wahlund L, Julin P, Linden DE, et al. Spatial pattern of cerebral glucose metabolism (PET) correlates with localization of intracerebral EEG-generators in Alzheimer's disease. Clin Neurophysiol. 2000;111(10):1817-24.

71. Babiloni C, Binetti G, Cassetta E, Dal Forno G, Del Percio C, Ferreri F, et al. Sources of cortical rhythms change as a function of cognitive impairment in pathological aging: a multicenter study. Clin Neurophysiol. 2006;117(2):252-68. https://doi.org/10. 1016/j.clinph.2005.09.019.

72. Babiloni C, Cassetta E, Binetti G, Tombini M, Del Percio C, Ferreri F, et al. Resting EEG sources correlate with attentional span in mild cognitive impairment and Alzheimer's disease. Eur J Neurosci. 2007;25(12):3742-57. https://doi.org/10.1111/j.14609568.2007.05601.x.

73. Gianotti LR, Kunig G, Lehmann D, Faber PL, Pascual-Marqui RD, Kochi K, et al. Correlation between disease severity and brain electric LORETA tomography in Alzheimer's disease. Clin Neurophysiol. 2007;118(1):186-96. https://doi.org/10.1016/j.clin ph.2006.09.007.

74. Babiloni C, Visser PJ, Frisoni G, De Deyn PP, Bresciani L, Jelic V, et al. Cortical sources of resting EEG rhythms in mild cognitive impairment and subjective memory complaint. Neurobiol Aging. 2010;31(10):1787-98. https://doi.org/10.1016/j. neurobiolaging.2008.09.020.

75. Babiloni C, Frisoni GB, Vecchio F, Lizio R, Pievani M, Cristina G, et al. Stability of clinical condition in mild cognitive impairment is related to cortical sources of alpha rhythms: an electroencephalographic study. Hum Brain Mapp. 2011;32(11): 1916-31. https://doi.org/10.1002/hbm.21157.

76. Nishida K, Yoshimura $M$, Isotani $T$, Yoshida $T$, Kitaura Y, Saito A, et al. Differences in quantitative EEG between frontotemporal dementia and Alzheimer's disease as revealed by LORETA. Clin 
Neurophysiol. 2011;122(9):1718-25. https://doi. org/10.1016/j.clinph.2011.02.011.

77. Caso F, Cursi M, Magnani G, Fanelli G, Falautano M, Comi G, et al. Quantitative EEG and LORETA: valuable tools in discerning FTD from AD? Neurobiol Aging. 2012;33(10):2343-56. https://doi.org/ 10.1016/j.neurobiolaging.2011.12.011.

78. Canuet L, Tellado I, Couceiro V, Fraile C, Fernandez-Novoa L, Ishii $\mathrm{R}$, et al. Resting-state network disruption and APOE genotype in Alzheimer's disease: a lagged functional connectivity study. PloS One. 2012;7(9):e46289. https://doi.org/10.1371/ journal.pone.0046289.

79. Hatz F, Benz N, Hardmeier M, Zimmermann R, Rueegg S, Schindler C, et al. Quantitative EEG and apolipoprotein E-genotype improve classification of patients with suspected Alzheimer's disease. Clin Neurophysiol. 2013;124(11):2146-52. https://doi. org/10.1016/j.clinph.2013.04.339.

80. Babiloni C, Lizio R, Del Percio C, Marzano N, Soricelli A, Salvatore E, et al. Cortical sources of resting state EEG rhythms are sensitive to the progression of early stage Alzheimer's disease. J Alzheimers Dis. 2013;34(4):1015-35. https://doi.org/10.3233/jad-12 1750 .

81. Lizio R, Del Percio C, Marzano N, Soricelli A, Yener GG, Basar E, et al. Neurophysiological assessment of Alzheimer's disease individuals by a single electroencephalographic marker. J Alzheimers Dis. 2016;49(1):159-77. https://doi.org/10.3233/jad-143 042.

82. da Silva FL. EEG: origin and measurement. Berlin: Springer; 2009. p. 19-38. https://doi.org/10.1007/ 978-3-540-87919-0_2.

83. Dierks T, Perisic I, Frolich L, Ihl R, Maurer K. Topography of the quantitative electroencephalogram in dementia of the Alzheimer type: relation to severity of dementia. Psychiatry Res. 1991;40(3): 181-94.

84. Nunez PL, Srinivasan R, Westdorp AF, Wijesinghe RS, Tucker DM, Silberstein RB, et al. EEG coherency: I: statistics, reference electrode, volume conduction, Laplacians, cortical imaging, and interpretation at multiple scales. Electroencephalogr Clin Neurophysiol. 1997;103(5):499-515. https://doi.org/10. 1016/S0013-4694(97)00066-7.

85. Srinivasan R, Winter WR, Ding J, Nunez PL. EEG and MEG coherence: measures of functional connectivity at distinct spatial scales of neocortical dynamics. J Neurosci Methods. 2007;166(1):41-52. https://doi.org/10.1016/j.jneumeth.2007.06.026.
86. Stam CJ, van Dijk BW. Synchronization likelihood: an unbiased measure of generalized synchronization in multivariate data sets. Physica D. 2002;163(3):236-51. https://doi.org/10.1016/S01672789(01)00386-4.

87. Pijnenburg YAL, Made Y, van Cappellen-van-Walsum AM, Knol DL, Scheltens P, Stam CJ. EEG synchronization likelihood in mild cognitive impairment and Alzheimer's disease during a working memory task. Clin Neurophysiol. 2004; 115(6):1332-9. https://doi.org/10.1016/j.clinph.2003. 12.029 .

88. Babiloni C, Ferri R, Moretti DV, Strambi A, Binetti $G$, Dal Forno G, et al. Abnormal fronto-parietal coupling of brain rhythms in mild Alzheimer's disease: a multicentric EEG study. Eur J Neurosci. 2004;19(9):2583-90. https://doi.org/10.1111/j.0953816X.2004.03333.x.

89. Babiloni C, Ferri R, Binetti G, Cassarino A, Dal Forno G, Ercolani M, et al. Fronto-parietal coupling of brain rhythms in mild cognitive impairment: a multicentric EEG study. Brain Res Bull. 2006;69(1): 63-73. https://doi.org/10.1016/j.brainresbull.2005. 10.013 .

90. Stam CJ, Nolte G, Daffertshofer A. Phase lag index: assessment of functional connectivity from multi channel EEG and MEG with diminished bias from common sources. Hum Brain Mapp. 2007;28(11): 1178-93. https://doi.org/10.1002/hbm.20346.

91. Koenig T, Lehmann D, Saito N, Kuginuki T, Kinoshita T, Koukkou M. Decreased functional connectivity of EEG theta-frequency activity in first-episode, neuroleptic-naive patients with schizophrenia: preliminary results. Schizophr Res. 2001;50(1-2):55-60.

92. Morrison JH, Rogers J, Scherr S, Levis DA, Campbell MJ, Bloom FE, et al. The laminar and regional distribution of neocortical somatostatin and neuritic plaques: implications for Alzheimer's disease as a global neocortical disconnection syndrome. The biological substrates of Alzheimer's disease. Orlando: Academic Press; 1996.

93. Lehmann D, Ozaki H, Pal I. EEG alpha map series: brain micro-states by space-oriented adaptive segmentation. Electroencephalogr Clin Neurophysiol. 1987;67(3):271-88.

94. Michel CM, Koenig T. EEG microstates as a tool for studying the temporal dynamics of whole-brain neuronal networks: a review. NeuroImage. 2018;180:577-93. https://doi.org/10.1016/j.neuro image.2017.11.062.

95. Pascual-Marqui RD, Michel CM, Lehmann D. Segmentation of brain electrical activity into 
microstates: model estimation and validation. IEEE Trans Biomed Eng. 1995;42(7):658-65. https://doi. org/10.1109/10.391164.

96. Koenig T, Prichep L, Lehmann D, Sosa PV, Braeker $\mathrm{E}$, Kleinlogel $\mathrm{H}$, et al. Millisecond by millisecond, year by year: normative EEG microstates and developmental stages. Neuroimage. 2002;16(1): 41-8. https://doi.org/10.1006/nimg.2002.1070.

97. Badhwar A, Tam A, Dansereau C, Orban P, Hoffstaedter F, Bellec P. Resting-state network dysfunction in Alzheimer's disease: a systematic review and meta-analysis. Alzheimer's Dement Diagn Assess Dis Monit. 2017;8:73-85. https://doi.org/10.1016/j. dadm.2017.03.007.

98. Lehmann D, Michel CM. Intracerebral dipole source localization for FFT power maps. Electroencephalogr Clin Neurophysiol. 1990;76(3):271-6.

99. Pascual-Marqui RD, Michel CM, Lehmann D. Low resolution electromagnetic tomography: a new method for localizing electrical activity in the brain. Int J Psychophysiol. 1994;18(1):49-65.

100. Blennow K, Hampel H, Weiner M, Zetterberg $\mathrm{H}$. Cerebrospinal fluid and plasma biomarkers in Alzheimer disease. Nat Rev Neurol. 2010;6(3):131-44. https://doi.org/10.1038/nrneurol.2010.4.

101. Blennow K. Cerebrospinal fluid protein biomarkers for Alzheimer's disease. NeuroRx. 2004;1(2):213-25.

102. Koenig T, Studer D, Hubl D, Melie L, Strik WK. Brain connectivity at different time-scales measured with EEG. Philos Trans R Soc Lond B Biol Sci. 2005;360(1457):1015-23. https://doi.org/10.1098/ rstb.2005.1649.

103. Babiloni C, Frisoni GB, Pievani M, Vecchio F, Lizio $\mathrm{R}$, Buttiglione $\mathrm{M}$, et al. Hippocampal volume and cortical sources of EEG alpha rhythms in mild cognitive impairment and Alzheimer disease. NeuroImage. 2009;44(1):123-35. https://doi.org/10.1016/ j.neuroimage.2008.08.005.

104. Babiloni C, Carducci F, Lizio R, Vecchio F, Baglieri A, Bernardini $S$, et al. Resting state cortical electroencephalographic rhythms are related to gray matter volume in subjects with mild cognitive impairment and Alzheimer's disease. Hum Brain Mapp. 2013;34(6):1427-46. https://doi.org/10. 1002/hbm.22005.

105. Babiloni C, Del Percio C, Boccardi M, Lizio R, Lopez $\mathrm{S}$, Carducci F, et al. Occipital sources of resting-state alpha rhythms are related to local gray matter density in subjects with amnesic mild cognitive impairment and Alzheimer's disease. Neurobiol Aging. 2015;36(2):556-70. https://doi.org/10.1016/ j.neurobiolaging.2014.09.011.
106. Foster NL, Chase TN, Mansi L, Brooks R, Fedio P, Patronas NJ, et al. Cortical abnormalities in Alzheimer's disease. Ann Neurol. 1984;16(6):649-54. https://doi.org/10.1002/ana.410160605.

107. Rapoport SI. Positron emission tomography in Alzheimer's disease in relation to disease pathogenesis: a critical review. Cerebrovasc Brain Metab Rev. 1991;3(4):297-335.

108. de Leon MJ, Mosconi L, Blennow K, DeSanti S, Zinkowski R, Mehta PD, et al. Imaging and CSF studies in the preclinical diagnosis of Alzheimer's disease. Ann N Y Acad Sci. 2007;1097:114-45. https://doi.org/10.1196/annals.1379.012.

109. Chetelat G, Desgranges B, de la Sayette V, Viader F, Eustache F, Baron JC. Mild cognitive impairment: can FDG-PET predict who is to rapidly convert to Alzheimer's disease? Neurology. 2003;60(8):1374-7.

110. Herholz K, Westwood S, Haense C, Dunn G. Evaluation of a calibrated (18)F-FDG PET score as a biomarker for progression in Alzheimer disease and mild cognitive impairment. J Nucl Med. 2011;52(8): 1218-26. https://doi.org/10.2967/jnumed.111. 090902.

111. Babiloni C, Del Percio C, Caroli A, Salvatore E, Nicolai E, Marzano N, et al. Cortical sources of resting state EEG rhythms are related to brain hypometabolism in subjects with Alzheimer's disease: an EEG-PET study. Neurobiol Aging. 2016;48: 122-34. https://doi.org/10.1016/j.neurobiolaging. 2016.08.021.

112. Slooter AJC, Cruts M, Kalmijn S, Hofman A, Breteler $\mathrm{MMB}$, Van Broeckhoven C, et al. Risk estimates of dementia by apolipoprotein e genotypes from a population-based incidence study: the Rotterdam study. JAMA Neurol. 1998;55(7):964-8. https://doi. org/10.1001/archneur.55.7.964.

113. Leoni V, Solomon A, Kivipelto M. Links between ApoE, brain cholesterol metabolism, tau and amyloid $\beta$-peptide in patients with cognitive impairment. Biochem Soc Trans. 2010;38(4):1021-5. https://doi.org/10.1042/bst0381021.

114. Castellano JM, Kim J, Stewart FR, Jiang H, DeMattos $\mathrm{RB}$, Patterson BW, et al. Human apoE isoforms differentially regulate brain amyloid-beta peptide clearance. Sci Transl Med. 2011;3(89):89ra57. https://doi.org/10.1126/scitranslmed.3002156.

115. Leoni V. The effect of apolipoprotein E (ApoE) genotype on biomarkers of amyloidogenesis, tau pathology and neurodegeneration in Alzheimer's disease. Clin Chem Lab Med. 2011;49(3):375-83. https://doi.org/10.1515/cclm.2011.088. 
116. Colloby SJ, Cromarty RA, Peraza LR, Johnsen K, Johannesson G, Bonanni L, et al. Multimodal EEGMRI in the differential diagnosis of Alzheimer's disease and dementia with Lewy bodies. J Psychiatr Res. 2016;78:48-55. https://doi.org/10.1016/j. jpsychires.2016.03.010.

117. Strijers RL, Scheltens P, Jonkman EJ, de Rijke W, Hooijer C, Jonker C. Diagnosing Alzheimer's disease in community-dwelling elderly: a comparison of EEG and MRI. Dement Geriatr Cogn Disord. 1997;8(3):198-202. https://doi.org/10.1159/000106 631.

118. Korczyn AD. Mixed dementia-the most common cause of dementia. Ann N Y Acad Sci. 2002;977: $129-34$.

119. Schneider JA, Arvanitakis Z, Bang W, Bennett DA. Mixed brain pathologies account for most dementia cases in community-dwelling older persons. Neurology. 2007;69(24):2197-204. https://doi.org/10. 1212/01.wnl.0000271090.28148.24.

120. Crary JF, Trojanowski JQ, Schneider JA, Abisambra JF, Abner EL, Alafuzoff I, et al. Primary age-related tauopathy (PART): a common pathology associated with human aging. Acta Neuropathol. 2014;128(6): 755-66. https://doi.org/10.1007/s00401-014-13490.

121. Murray ME, Cannon A, Graff-Radford NR, Liesinger AM, Rutherford NJ, Ross OA, et al. Differential clinicopathologic and genetic features of late-onset amnestic dementias. Acta Neuropathol. 2014; 128(3):411-21. https://doi.org/10.1007/s00401-0141302-2.

122. Nelson PT, Dickson DW, Trojanowski JQ, Jack CR, Boyle PA, Arfanakis K, et al. Limbic-predominant age-related TDP-43 encephalopathy (LATE): consensus working group report. Brain. 2019. https:// doi.org/10.1093/brain/awz099.

123. Vogel F. The genetic basis of the normal human electroencephalogram (EEG). Humangenetik. 1970;10(2):91-114.

124. Sleimen-Malkoun R, Perdikis D, Müller V, Blanc J-L, Huys R, Temprado J-J, et al. Brain dynamics of aging: multiscale variability of EEG signals at rest and during an auditory oddball task. eNeuro. 2015. https://doi.org/10.1523/eneuro.0067-14.2015.

125. Andersson M, Hansson O, Minthon L, Rosen I, Londos E. Electroencephalogram variability in dementia with lewy bodies, Alzheimer's disease and controls. Dement Geriatr Cogn Disord. 2008;26(3): 284-90. https://doi.org/10.1159/000160962.

126. Stylianou M, Murphy N, Peraza LR, Graziadio S, Cromarty R, Killen A, et al. Quantitative electroencephalography as a marker of cognitive fluctuations in dementia with Lewy bodies and an aid to differential diagnosis. Clin Neurophysiol. 2018;129(6):1209-20. https://doi.org/10.1016/j. clinph.2018.03.013.

127. Lehmann C, Koenig T, Jelic V, Prichep L, John RE, Wahlund LO, et al. Application and comparison of classification algorithms for recognition of Alzheimer's disease in electrical brain activity (EEG). J Neurosci Methods. 2007;161(2):342-50. https:// doi.org/10.1016/j.jneumeth.2006.10.023.

128. Prichep LS. Quantitative EEG and electromagnetic brain imaging in aging and in the evolution of dementia. Ann N Y Acad Sci. 2007;1097:156-67. https://doi.org/10.1196/annals.1379.008.

129. Jelic V, Östberg P, Wahlund L-O, Koenig T. Decreased global field synchronization (GFS) is an EEG classifier of frontotemporal dementia. In: 10th international conference on frontotemporal dementias, 31 Aug-2 Sep, Munich, Germany. 2016. (Journal of Neurochemistry, vol. 138 Special Issue: Frontotemporal dementias: From molecular mechanisms to therapy).

130. Babiloni C, Binetti G, Cassetta E, Cerboneschi D, Dal Forno G, Del Percio C, et al. Mapping distributed sources of cortical rhythms in mild Alzheimer's disease. A multicentric EEG study. Neuroimage. 2004;22(1):57-67. https://doi.org/10. 1016/j.neuroimage.2003.09.028.

131. McKeith I, Mintzer J, Aarsland D, Burn D, Chiu H, Cohen-Mansfield J, et al. Dementia with Lewy bodies. Lancet Neurol. 2004;3(1):19-28. https://doi. org/10.1016/s1474-4422(03)00619-7.

132. van der Zande JJ, Gouw AA, van Steenoven I, Scheltens P, Stam CJ, Lemstra AW. EEG characteristics of dementia with Lewy bodies, Alzheimer's disease and mixed pathology. Front Aging Neurosci. 2018;10:190. https://doi.org/10.3389/fnagi.2018. 00190 .

133. Kai T, Asai Y, Sakuma K, Koeda T, Nakashima K. Quantitative electroencephalogram analysis in dementia with Lewy bodies and Alzheimer's disease. J Neurol Sci. 2005;237(1-2):89-95. https://doi. org/10.1016/j.jns.2005.05.017.

134. Briel RC, McKeith IG, Barker WA, Hewitt Y, Perry $\mathrm{RH}$, Ince PG, et al. EEG findings in dementia with Lewy bodies and Alzheimer's disease. J Neurol Neurosurg Psychiatry. 1999;66(3):401-3. https:// doi.org/10.1136/jnnp.66.3.401.

135. McKeith IG, Dickson DW, Lowe J, Emre M, O’Brien JT, Feldman H. Diagnosis and management of dementia with Lewy bodies: third report of the DLB 
Consortium. Neurology. 2005. https://doi.org/10. 1212/01.wnl.0000187889.17253.b1.

136. Aoki Y, Kazui H, Pascal-Marqui RD, Ishii R, Yoshiyama $\mathrm{K}$, Kanemoto $\mathrm{H}$, et al. EEG resting-state networks in dementia with Lewy bodies associated with clinical symptoms. Neuropsychobiology. 2019;77(4):206-18. https://doi.org/10.1159/000495620.
137. Garn H, Coronel C, Waser M, Caravias G, Ransmayr G. Differential diagnosis between patients with probable Alzheimer's disease, Parkinson's disease dementia, or dementia with Lewy bodies and frontotemporal dementia, behavioral variant, using quantitative electroencephalographic features. J Neural Transm (Vienna). 2017;124(5):569-81. https://doi.org/10.1007/s00702-017-1699-6. 